\title{
Cardiovascular magnetic resonance-derived aortic compliance, distensibility and pulse wave velocity at rest and during a supine bicycle exercise in young adults: A pilot study
}

\author{
Laurence Bal-Theoleyre ${ }^{1,2}$, Alain Lalande ${ }^{3}$, Frank Kober ${ }^{2}$, Monique Bernard ${ }^{2}$, Alexis Jacquier ${ }^{1,2^{*}}$ \\ From 17th Annual SCMR Scientific Sessions \\ New Orleans, LA, USA. 16-19 January 2014
}

\section{Background}

Purpose: Risk of aortic rupture is evaluated based on the vessel diameter; this parameter is probably insufficient. In vivo evaluation of biomechanical property of the aortic tissue might be of interest to discriminate between normal and altered aortic tissue (A Lalande et al, JMRI 2008). The purpose of this study was to describe a technique to measure regional aortic compliance (AC), aortic distensibility (AD) and aortic stiffness with $1.5 \mathrm{~T}$ MRI in young individuals under resting conditions and during supine bicycle exercise.

\section{Methods}

Materials and Methods: Fiftheen young adults ( 8 men, median 29 (23-41) yrs) with no risk factor for atherosclerosis were recruited. They all underwent 1.5T MRI (Siemens, Avanto) at rest and during supine exercise using an amagnetic ergometer (Lode, the Netherlands). The following parameters were used for rest and exercise: cine $=\mathrm{TR} / \mathrm{TE}=30 \mathrm{~ms} / 1.8 \mathrm{~ms}$, thickness $=6 \mathrm{~mm}$, $\alpha=65^{\circ}$, matrix $=148 \times 256$, resolution $=30 \mathrm{~ms}$, retrospective gating; Phase contrast $=\mathrm{TR} / \mathrm{TE}=25 \mathrm{~ms} / 2 \mathrm{~ms}$, thickness $=6 \mathrm{~mm}$, matrix $=256 \times 256$, flow encoding $=$ $200 \mathrm{~cm} / \mathrm{s}, \alpha=25^{\circ}$, resolution $=25 \mathrm{~ms}$, retrospective gating). For exercise the volunteer was instructed to cycle for $2 \mathrm{~min}$ at $25 \mathrm{~W}$, work load was increased each $2 \mathrm{~min}$ for a minimum of $10 \mathrm{~min}$, to obtained twice the resting heart rate. The volunteer was instructed to stop cycling and immediately following which a breath held stress dataset of 2 acquisitions were acquired. The volunteer

${ }^{1}$ Radiology, APHM, Marseille, France

Full list of author information is available at the end of the article was instructed to cycle for at least $2 \mathrm{~min}$ at the last exercise level, and the images acquisition was repeated. $A C$ and $A D$ were determined from cine-MRI at four locations, ascending aorta (AA), proximal descending aorta (PDA), distal descending aorta (DDA), and aorta above renal artery (RA). Segmental aortic pulse wave velocity (PWV) was assessed by phase contrast.

\section{Results}

Results All volunteer complete the whole protocol. Stress induced a significant decrease of $\mathrm{AC}$ and $\mathrm{AD}$ at all sites $(\mathrm{p}<10-3)$. At rest and during stress, AC was statistically higher in AA compared to the whole descending aorta ( $\mathrm{p} \leq 0.0007)$. We found a strong correlation between the rate pressure product and $\mathrm{AC}$ at all sites (Figure 1). During exercise we measure a reduction of the aortic maximal diameter along the aortic arch (AA, $\mathrm{p}=0.06$ and PDA, $\mathrm{p}=0.008)$ suggesting a contraction of the thoracic aorta during exercise. PWV measured at PDA and DDA increased significantly during stress $(\mathrm{p}=$ $0.02, \mathrm{p}=0.008$, respectively).

\section{Conclusions}

Conclusion This study demonstrates the feasibility to analyze regional aortic function during an exerciseinduced stress MRI. Further studies are required to evaluate its interest to detect AA's dysfunction among patients with thoracic aortic diseases.

\section{Funding}

Not applicable. 


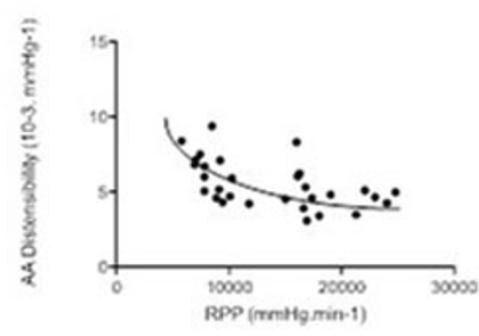

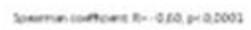

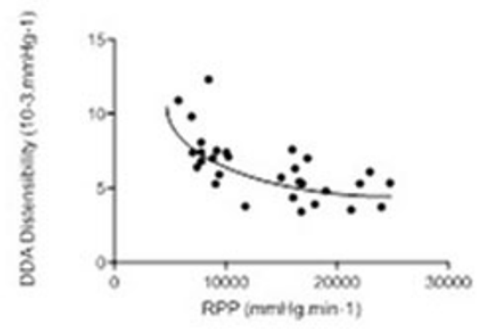

semencenthe or mesce

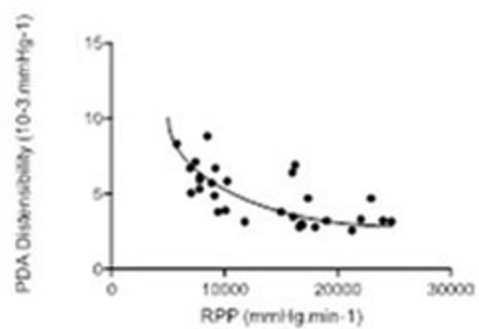

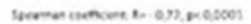

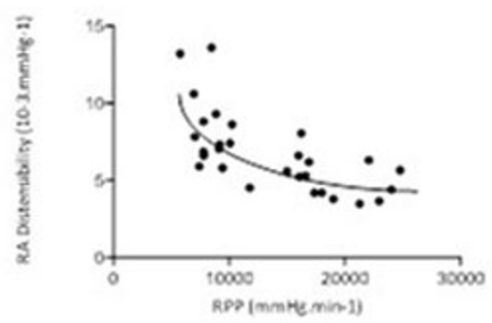

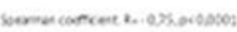

\section{Regional aortic distensibility and cardiac work correlation.}

RPP = cardiac work indice theart rate " systolic pressurel, in mmHg min"

AA: ascending sortx, POA: proximal descending artx D DA: distal descending sortx, RA renal aort;

Figure 1

\section{Authors' details}

'Radiology, APHM, Marseille, France. ${ }^{2}$ CEMEREM - CNRS 7339, Faculté de Médecine, Marseille, France. ${ }^{3}$ Le2i - UMR CNRS 6306, Faculté de Médecine, Dijon, France.

Published: 16 January 2014

doi:10.1186/1532-429X-16-S1-P171

Cite this article as: Bal-Theoleyre et al: Cardiovascular magnetic resonance-derived aortic compliance, distensibility and pulse wave velocity at rest and during a supine bicycle exercise in young adults: A pilot study. Journal of Cardiovascular Magnetic Resonance 2014 16(Suppl 1): P171.

Submit your next manuscript to BioMed Central and take full advantage of:

- Convenient online submission

- Thorough peer review

- No space constraints or color figure charges

- Immediate publication on acceptance

- Inclusion in PubMed, CAS, Scopus and Google Scholar

- Research which is freely available for redistribution

Submit your manuscript at www.biomedcentral.com/submit 